\title{
PENAFSIRAN ALI AL-SHABUNI TENTANG AYAT-AYAT YANG BERKAITAN DENGAN TEOLOGI
}

\author{
Aji Fatahilah, Ahmad Izzan, Erni Isnaeniah \\ Fakultas Ushuluddin UIN Sunan Gunung Djati Bandung \\ Jl. AH. Nasution No. 105 Bandung \\ Email: ajifatahillah@gmail.com
}

\begin{abstract}
This research explores the interpretation of Ali Al-Shabuni on ru'yatullah and the nature of God categorised as Anthropomorphism. This research aims to understand Ali Al-Shabuni's characteristic in interpreting verses related to Islamic theology especially on ru'yatullah and God's deed which usually called anthropomorphism. This research employs descriptive-analysis to the primary source of Tafsir Sofwatuttafasir by Ali Al-Shabuni. This research shows that Ali Al-Shabuni interpretation on ru'yatullah in verse al-Qiyamah [75]: 22-23 tended to support the opinion of Ahlussunnah that God can be seen in the afterlife. Ali Al-Shabuni interpretation on an-Nisa [4]: 164 that related to God speaks to Musa is also in line with Asy'ariyah theological doctrin that God speaks directly to him. In addition, when Ali Al-Shabuni interpreted the verse as-Sajdah [32]: 4 that related to anthropomorphism agreed with ahlussunnah. For example the word بيََيَى in verse Shaad [38]: 75 is interpreted using two methods of tafwidh and takwil. Overall, Ali Al-Shabuni's interpretation on ru'yatullah, anthropomorphism and God's deed supported the theology of Ahlussunnah (Asy'ariyyah).
\end{abstract}

Keywords:

interpretation; theology; anthrofomorphisme; ru'yatullah.

\begin{abstract}
Abstrak
Penelitian ini mengkaji penafsiran Ali al-Shabuni tentang ru'yatullah dan sifat-sifat Allah yang dianggap anthrofomorphisme. Tujuan penelitian ini yaitu, untuk mengetahui kecenderungan Ali al-Shabuni dalam menafsirkan ayat-ayat yang berkaitan dengan wacana teologi, terutama tentang ru'yatullah dan anthrofomorphisme serta perbuatan Tuhan (afal Allah) dan manusia). Metode yang digunakan ialah deskriptif-analitis. Sumber primernya yaitu kitab Shafwah al-Tafâsîr karya Ali al-Shabuni. Penelitian ini menemukan bahwa ketika Ali alShabuni menafsirkan tentang ru'yatullah dalam surat al-Qiyamah [75]: 22-23, ia sepaham dengan teologi ahlu al sunnah yang berpendapat bahwa Tuhan bisa dilihat di akhirat kelak. Dalam menafsirkan surat an-Nisa [4]: 164 tentang Allah berbicara dengan Musa, ia pun cenderung dengan teologi Asy'ari, bahwasannya Allah berbicara dengan Musa secara langsung. Demikian pula ketika menafsirkan masalah anthropomorfhisme dalam surat asSajdah [32]: 4, Ali al-Shabuni sepaham dengan teologi Asy’ari. Dalam menafsirkan kata بيَّ pada surat Shaad [38]: 75, cenderung berwarna ahlu al-sunnah karena dalam memahami ayat seperti ini ahlu al-sunnah menggunakan dua metode, yaitu tafwidh dan takwil. Demikian pula ketika memahami perbuatan Tuhan dan manusia yaitu surat alSaffat [37]: 96, sepaham dengan teologi Asy'ari yang mengatakan bahwa Allah yang menciptakan kalian dan perbuatan kalian. Secara umum, dalam menafsirkan ayat-ayat teologi cenderung mengikuti teologi ahlussunnah Asy'ariah.
\end{abstract}

Kata Kunci:

penafsiran; teologi; anthrofomorphisme; ru'yatullah.

\section{A. PENDAHULUAN}

Islam merupakan agama peradaban. Tradisi penafsiran Alquran setiap zamannya memiliki epistemologinya tersendiri. Abdul Mustakim memapaparkan tentang epistemologi tafsir dari periode klasik hingga kontemporer ${ }^{1}$ :

\footnotetext{
${ }^{1}$ Abdul Mustakim, Pergeseran Epistemologi Tafsir, (Yogyakarta: Pustaka Pelajar, 2008), 72.
}

Pertama, masa awal, dimulai sejak zaman Rasulullah SAW hingga kurang lebih abad II Hijriyah, sumber tafsirnya Alquran, al-Hadits, qiraat, aqwal dan ijtihad sahabat, tabi'in, cerita israiliyyat, syair-syair jahiliyah. Kedua, masa pertengahan antara abad II $\mathrm{H}$ hingga pertengahan abad VIII H (VII M hingga XIV M), dan abad selanjutnya hingga abad ke XVIII H. Sumber tafsir akal lebih dominan dari pada Alquran dengan hadits. Teori-teori 
keilmuan filsafat, tasawuf, ilmu kalam dan sebagainya yang ditekuni mufasir, dengan analisis kebahasaan serta teori-teori dari disiplin keilmuan atau madzhab masingmasing mufasir. Pada abad ini kita bisa menemukan kitab-kitab tafsir dari berbagai corak keilmuan dan latar belakang madzhab yang berbeda-beda. Ahli ilmu-ilmu rasional akan mengkonsentrasikan dalam tafsirnya pendapat-pendapat para filosof seperti alFakhrurrazi. Ahli fikih akan mengkonsentrasikan penafsirannya pada masalah-masalah fikih, seperti al-Jahshash, al-Qurtubi. Begitu juga dengan pengaruh madzhab. Mufasir yang mempunyai madzhab ideologis dalam penafsirannya, seperti Zamakhsyari dari kaum Muktazilah dan Mulla Muhsin al-Kasyi dari Syi'ah Imamiyah ${ }^{2}$, yang penafsirannya banyak dipengaruhi oleh madzhabnya. al-Dzahabi mengatakan, munculnya berbagai madzhab keagamaan sangat mempengaruhi tafsir Alquran. Hal itu terjadi karena Alquran merupakan acuan pertama bagi kaum Muslimin pendukung madzhab-madzhab tersebut. Mereka berusaha mencari dalil untuk mendukung madzhabnya masing-masing, meskipun dengan cara mencocok-cocokan teks (nash) Alquran dengan pandangan madzhabnya itu. ${ }^{3}$ Menurut Badri Khaeruman dalam bukunya sejarah tafsir Alquran mengatakan, munculnya aliran kalam mempunyai pengaruh besar terhadap kemunculan aliran tafsir bil ar-ra'yi. Oleh karena itu, suatu aliran dipastikan untuk menggunakan logika alirannya dalam menafsirkan Alquran. Teologi yang dianutnya sangat berperan, dan dalil-dalil yang diperoleh akan diarahkan kepada logika

2 Yunus Hasan Abidu, Tafsir al-Quran Sejarah Tafsir dan Metode Para Mufasir, terj. Oleh Qodirun Nur dan Ahmad Musyafiq Dari Judul Asli Dirasat Wa Mabahits Fi Tarikh al-Tafsir Wa Manahij alMufassirin, (Jakarta: Gaya Media Pratama, 2007), 15.

33 M. Husein al-Dzahabi, Penyimpanganpenyimpangan Dalam Penafsiran al Quran,Diterjemahkan oleh, Hamim Ilyas dan Mazhnun Husein Dari Judul Asli, Al-Ittija Hatul Munharifah Fi Tafsiril Quranil Karim, Ed. 1, Cet. 4, (Jakarta: PT Raja Grafindo Persada, 1996), 53. teologinya. ${ }^{4}$ Oleh karena itu Goldziher mengatakan, arus pemikiran mufasir yang muncul senantiasa cenderung mencari justifikasi kebenaran bagi dirinnya, dan menjadikan Alquran sebagai sandaran untuk menunjukan kesesuaian pemikirannya dengan Islam dan dengan apa yang dibawa Rasulullah SAW. ${ }^{5}$

Ketiga, masa modern-kontemporer. Struktur epistemologi sebagai berikut, sumber tafsir Alquran, realitas, akal, yang berdialektika secara sirkular dan fungsional. Sumber hadits jarang digunakan ${ }^{6}$.

Pada masa kontemporer ini lahir kitab Shafwah al-Tafâsîr karangan al-Shabuni. Shafwah al-Tafâsîr merupakan tafsir ringkas, meliputi semua ayat Alquran sebagaimana yang terdapat dalam judul kitab: Jami' baina al-Ma'tsur wa al-Ma'qul. Shafwah al-Tafâsîr ini berpedoman kepada sumber-sumber primer seperti al-Thabari, al-Kasysyaf (Zamkhsyari), ruh al-Ma'ânî (al-Alusi), tafsir Alquran al'Azhîm (Ibn Katsir), Bahr al-Muhith (Abu Hayyan), mafatih al-Ghaib (al-Razi) dan lainlain dengan redaksi yang mudah dipahami, serta berpedoman pada teknik penulisan ilmiah modern. ${ }^{7}$ Diantara sumber-sumber yang diambil dalam tafsir ini adanya sumbersumber tafsir dengan latar belakang ideologi yang berbeda. Seperti tafsir al-Kasysyaf karya Zamakhsyari yang muktazili, al-Razi yang Asy'ari dan ibn Katsir serta al-Thabari yang salafi. Walaupun demikian, menurut Husnul Hakim Imzi, dalam persoalan kalam, Ali alShabuni berpedoman pada mazhab ahlussunnah Asy'ariah. Oleh karena itu penulis akan meneliti lebih lanjut mengenai

\footnotetext{
${ }^{4}$ Badri Khaeruman, Sejarah Perkembangan Tafsir al-Quran, (Bandung: Pustaka Setia, 2004), 133.

${ }^{5}$ Ignaz Goldziher, Mazhab Tafsir dari Aliran Klasik Hingga Modern, terj. Oleh M. Alaika Salamullah, Saifydin Zuhri dan Badrus Syamsul Fata, cet. 1, (Yogyakarta: Elsaq Press, 2003), 3.

${ }^{6}$ Riki Saputra, "Religion And The Spiritual Crisis Of Modern Human Being In The Perspective Of Huston Smith 'S Perennial Philosophy," Al-Albab 5, no. 2 (2016): 195-215.

7 A. Husnul Hakim Imzi, Ensiklopedi Kitab-kitab Tafsir Kumpulan Kitab-kitab Tafsir Dari Masa Klasik Sampai Masa Kontemporer, Cet. 1, (Depok: LSIQ, 2013), 208.
} 
penafsirannya dalam masalah teologi, apakah benar ia terpengaruhi oleh teologi Asy'ari atau tidak serta penulis akan membatasi ayat-ayat teologinya, yaitu tentang ru'yatullah, sifat Allah dan anthropomorfisme, serta perbuatan Tuhan dan manusia. Seperti ungkapan Hikmawati dalam tulisannya, bahwa al-Quran adalah basis untuk mengatasi segala masalah maka dari itu kajian ini sangat menarik, "Putting the "al-Qur'an" as a basis to resolve various problems of life, so it can maintain religious commitment to students' self as "the noblest creature of God" (khalifatullah fil ardl)" 8 .

\section{B. HASIL DAN PEMBAHASAN}

\section{Wacana Teologi Islam dan Pengaruhnya} Terhadap Penafsiran Alquran

\section{a. Pengertian Teologi}

Makna teologi secara etimologis terdiri dari kata Teo berarti Tuhan dan logi yang berarti ilmu.Teologi berarti ilmu yang membahas dan berhubungan dengan masalah ketuhanan. Teologi sering disebut dengan ilmu kalam. Menurut Ibn Khaldun yang dikutip oleh A. Hanafi, ilmu kalam ialah ilmu berisi alasanalasan yang mempertahankan kepercayaankepercayaan iman dengan menggunakan dalildalil fikiran yang berisi bantahan-bantahan terhadap orang-orang yang menyeleweng dari kepercayaan-kepercayaan aliran golongan salaf dan Ahli Sunnah. ${ }^{9}$ Sedangkan Muhammad Abduh berpendapat bahwa ilmu kalam merupakan ilmu yang membicarakan tentang wujud Tuhan (Allah), sifat-sifat yang mesti ada pada-Nya, sifat-sifat yang mesti tidak ada pada-Nya serta sifat-sifat yang mungkin ada pada-Nya, dan membicarakan pula tentang rasul-rasul Tuhan, untuk menetapkan kerasulannya dan mengetahui sifat-sifat yang mesti ada pada dirinya, sifatsifat yang mesti tidak ada padanya serta sifat-

\footnotetext{
${ }^{8}$ Fenti Hikmawati, "Islamic Counselling Model to Increase Religious Commitment (Study of Students at the University UIN Bandung)," International Journal of Nusantara Islam 1, no. 1 (2013): 65-81.

${ }^{9}$ Ahmad Hanafi, Theologi Islam (Ilmu Kalam), cet. 3, (Jakarta: Bulan Bintang, 1979), 10.
}

sifat yang mungkin ada padanya dan sifat-sifat yang mungkin terdapat padanya. ${ }^{10}$

\section{b. Hubungan Tafsir dan Ideologi Mufasir}

Abdul Mustaqim membaginya menjadi tiga berdasarkan perspektif The History Of Idea, yaitu:

\section{1) Tafsir era formatif dengan nalar mitis.}

Adapun karakteristiknya yaitu, minimnya budaya kritisisme, penafsirannya masih bersifat global, praktis dan implementatif.Tujuan penafsiran relative sekedar memahami makna. ${ }^{11}$

\section{2) Tafsir era afirmatif dengan nalar ideologis.}

Adapun karakteristiknya yaitu, ideologis, sekterian, automistic, repetitive, pemaksaan gagasan dan subjektif. Sedangkan tujuannya pada era ini adalah, untuk kepentingan kelompok, mendukung kekuasaan, madzhab atau ilmu yang ditekuni mufasir. Era ini terjadi pada zaman akhir Dinasti Umayah dan awal Dinasti Abbasiyah. Terutama saat masa khalifah Harun ar-Rasyid yang munculnya gerakan intelektual Islam dan fanatisme madzhab. ${ }^{12}$

\section{3) Tafsir era reformatif dengan nalar kritis \\ Karakteristiknya yaitu, kritis,} transformative, solutif dan non ideologis. Adapun tujuannya untuk transformasi dan perubahan. $^{13}$

Dari penjelasan diatas nampak jelas, bahwa tiap-tiap periode mufasir tak lepas dari episteme-episteme yang digunakan dalam penafsiran, serta adannya faktor internal seperti keilmuan mufasir, maupun faktor eksternal. "As we know that Islam is one religion that attracted so many scientists and researchers." 14 seperti situasi-kondisi, politik juga madzhab-madzhab keagamaan yang

\footnotetext{
${ }^{10}$ Abuddin Nata, Metodologi Studi Islam, , cet. 20, (Jakarta: Rajawali Pers, 2013), 21.

11 Abdul Mustaqim, Pergeseran Epistemologi Tafsir, (Yogyakarta: Pustaka Pelajar, 2008), 58.

12 Abdul Mustaqim, Pergeseran Epistemologi Tafsir, 72.

${ }^{13}$ Abdul Mustaqim, Pergeseran Epistemologi Tafsir, 113.

${ }^{14}$ Masripah, "Indonesian Islamic Women Movement (A Case Study of Bkswi West Java)," International Journal of Nusantara Islam 1, no. 2 (2013): 9-21.
} 
melatarbelakangi keideologian mufasir. Tafsir adalah inti ajaran Islam yang paling dijaga ortodoksinya. ${ }^{15}$

Ideologi secara umum dapat diartikan suatu kumpulan gagasan, ide-ide, keyakinan serta kepercayaan yang dimiliki manusia. Dalam pengertian yang lebih spesifik, ideologi adalah suatu sistem gagasan, keyakinan dan sikap yang mendasari cara hidup suatu kelompok atau masyarakat. Oleh karenannya, ideologi senantiasa terikat oleh kepercayaan atau pemahaman kelompok yang berimbas pada seseorang. Hal ini pun bisa terlihat dalam diri mufasir ketika menafsirkan al-Quran. Karena Alquran merupakan teks yang harus dihidupkan, dan oleh karenannya manusia mempunyai peran penting dalam menggali dan menjelaskan isi dari kandungan teks Alquran. Sebagaimana yang diungkapkan oleh Ali ibn Abi Thalib, " tanpa manusia, Alquran tak bisa berbicara apa-apa." Studi Alquran dapat mendukung upaya integrasi keilmuan dengan cara akomodasi penemuan ilmiah yang sistematis dengan tetap mengacu pada basis kewahyuan Alquran. ${ }^{16}$

Seperti al-Razi yang ahli dalam ilmu-ilmu rasional. Ia banyak menguraikan masalahmasalah teologi yang dalam ini mengikuti ahlussunnah, pendapat-pendapat para filsuf, kerancuan mereka dan sanggahannya terhadap mereka, sehingga menjadi pilar bagi ilmu-ilmu rasional. ${ }^{17}$ Ada yang mumpuni dibidang fiqih, seperti al-Qurthubi dengan kitab tafsirnya alJami' li Ahkam Alquran, dan Qadhi Abu Bakar ibn al-Arabi. Keduannya sangat mumpuni dibidang fiqih, sehingga memberi perhatian lebih pada masalah-masalah furu'iah fiqhiyah, mengukuhkan dalil-dalilnya dan

${ }^{15}$ Rosihon Anwar, Dadang Darmawan, and Cucu Setiawan, "Kajian Kitab Tafsir Dalam Jaringan Pesantren Di Jawa Barat," Wawasan: Jurnal Ilmiah Agama Dan Sosial Budaya 1, no. 1 (2016): 56.

16 Syahrullah Iskandar, "Studi AlQuran Dan Integrasi Keilmuan: Studi Kasus UIN Sunan Gunung Djati Bandung," Wawasan: Jurnal Ilmiah Agama Dan Sosial Budaya 1, no. 1 (2016): 86.

17 Yunus Hasan Abidu, Tafsir al-Qur'an Sejarah Tafsir dan Metode Para Mufasir, terj. Qodirun Nur dan Ahmad Musyafiq, (Jakarta: Gaya Media Pratama, 2007), 104-105. menyanggah orang-orang yang berbeda pendapat. Ada juga yang ahli isyarat dan para pelaku tasawuf.Mereka member perhatian kepada masalah tarhib, targhib, zuhud, ridla dan lain-lain. Seperti tafsir Ibn Arabi. ${ }^{18}$

\section{c. Pengaruh teologi Mufasir Dalam Menafsirkan Ayat-Ayat Teologi}

Al-Dzahabi mengatakan, munculnya berbagai madzhab keagamaan sangat mempengaruhi tafsir Alquran. Hal itu terjadi karena Alquran merupakan acuan pertama bagi kaum Muslimin pendukung madzhabmadzhab tersebut. Mereka berusaha mencari dalil untuk mendukung madzhabnya masingmasing, meskipun dengan cara mencocokcocokan teks (nash) Alquran dengan pandangan madzhabnya itu. ${ }^{19}$ Senada dengan itu Badri Khaeruman dalam bukunya sejarah tafsir Alquran mengatakan, munculnya aliran kalam mempunyai pengaruh besar terhadap kemunculan aliran tafsir bil ar-ra'yi. Oleh karena itu, suatu aliran dipastikan untuk menggunakan logika alirannya dalam menafsirkan Alquran. Teologi yang dianutnya sangat berperan, dan dalil-dalil yang diperoleh akan diarahkan kepada logika teologinya. Dalam sejarahnya,kajian teologi, seperti teologi pembebasan merupakan studi kritis tentang fenomena sosial yang telah banyak dikembangkan para ilmuwan sosial dalam mengkaji studi agama dan perubahan sosial. ${ }^{20}$

Seperti dalam menafsirkan إلى رَبِّهَا نَاظِرَهُ pada surat al-Qiyamah ayat 22-23, menurut Zamakhsyari yang bermadzhab muktazilah, kalimat itu bukanlah taqdim al-maf'ul melainkan adannya pentakdiran terhadap kata nikmat. Kata "nadzirah", menurutnya berarti "al-Raja", yang berarti maknanya intazhara ila ni'matillah (menunggu nikmat Tuhan). ${ }^{21}$

\footnotetext{
${ }^{18}$ Yunus Hasan Abidu, Tafsir al-Qur'an Sejarah Tafsir dan Metode Para Mufasir, 105.
}

19 M. Husein al-Dzahabi, Penyimpanganpenyimpangan Dalam Penafsiran al Quran,terj. Oleh Hamim Ilyas dan Mazhnun Husein Dari Judul Asli, AlIttija Hatul Munharifah Fi Tafsiril Quranil Karim, Ed. 1, Cet. 4, (Jakarta: PT Raja Grafindo Persada, 1996), 53

${ }^{20}$ Badri Khaeruman, Sejarah Perkembangan Tafsir al-Quran, (Bandung: Pustaka Setia, 2004), 133.

${ }^{21}$ Zamakhsyari, al-Kasysyaf, CD al-Maktabah asySyamilah 
Hal ini dilakukan agar sesuai dengan ideologi muktazilah yang berpendapat bahwa Tuhan tidak bisa dilihat diakhirat kelak. Sedangkan menurut al-Razi, sebagai perwakilan dari Sunni, kalimat diatas adalah taqdim al-Maf'ul sehingga bermakna khusus. Sehingga menurutnya bahwa Tuhan bisa dilihat diakhirat kelak. ${ }^{22}$

\section{Analisis Penafsiran Ali Al-Shabuni Dalam Tafsir Shafwah Al- Tafâsîr \\ a. Biografi Muhammad Ali al-Shabuni}

Nama lengkap beliau adalah Muhammad 'Ali bin Jamil al-Shabuni. Beliau adalah salah satu Guru Besar di Fakultas Syariah dan Diwasat Islamiyah, Universitas Ummul Qura, Makkah. Beliau dilahirkan di Halb pada 1374 H/1928 M. Beliau lulus dari tingkat menengah atas di Syiria. Lalu melanjutkan ke jenjang perguruan tinggi di Universitas al-Azhar, Mesir. Pada 1371 H/1952 M, beliau memperoleh ijazah master (S2) dalam bidang Peradilan Islam. Kemudian melanjutkan di tingkat doktoral di kampus yang sama atas biaya Kementrian Wakaf Syiria. ${ }^{23}$ Adapun karya-karya beliau adalah sebagai berikut:

a. Tafsir Shafwah al-Tafâsîr

b. Rawa'I al-Bayan Fi Tafsir Ayat al-Ahkam

c. Al-Tibyan Fi Ulum Alquran

d. Nubuwwah al-Anbiya

e. Mukhtasar Tafsir ibn Katsir

f. Mukhtasar Tafsir at-Thabari

g. Qabs Min Nur al-Quran

h. Tanwiru al-Adzhan Min Tafsir Ruh alBayan

i. Al-Mawarits Fi al-Syari'ah al-Islamiyyah 'Ala Dhu'i al-Kitab wa al-Sunnah

\section{b. Karakteristik Tafsir Shafwah al-Tafâsîr}

1) Latar Belakang Penulisan Shafwah alTafâsîr

Dalam muqaddimahnya, ia menamai Shafwah al-Tafâsîr karena memuat inti dari kitab-kitab tafsir besar yang disusun lebih

\footnotetext{
22 Fachrudin al-Razi, Mafatih al-Ghaib, CD alMaktabah asy-Syamilah

23 A. Husnul Hakim Imzi, Ensiklopedi Kitab-kitab Tafsir Kumpulan Kitab-kitab Tafsir Dari Masa Klasik Sampai Masa Kontemporer, Cet. 1, (Depok: LSIQ, 2013), 207.
}

ringkas, tertib, mudah dan jelas. Dengan harapan memberikan manfaat bagi umat Islam dengan penjelasannya. ${ }^{24}$

\section{2) Sumber metode dan corak Shafwah al- \\ Tafâsîr}

Shafwah al-Tafâsîr ini menggabungkan dua metode, yaitu bi al-ma'tsur dan bi al-ma'qul. Penulis berpedoman kepada sumber-sumber primer, seperti Jami' al-Bayân (al-Thabari), al-Kasysyâf (Zamakhsyari), Ruh al-Ma'ani (al-Alusi), Tafsir Alquran al-'Adzhim (iIbn Katsir), al-Bahr al-Muhith (Abu Hayyan), dan lain-lain. ${ }^{25}$

Adapun dalam menafsirkan ayat ia menafsirkannya tidak terlalu panjang dan melebar. Oleh karena itu, penulis berasumsi atau berkesimpulan bahwa metode umum yang dipakai oleh al-Shabuni dalam menafsirkan Alquran didalam kitab Shafwah al-Tafâsîr termasuk kedalam metode Ijmali.

Diantara karakteristik tafsir ini adalah menyebutkan kesimpulan dan memilih sumber penafsirannya dari sumber-sumber primer. Sesuai dengan penulisan ilmiah modern, alShabuni menyebutkan sumber-sumber pengutipannya di footnote. Beliau tidak selalu membandingkan beberapa pendapat tersebut, terkadang ditarjih atau dijadikan sebagai penguat dari penafsirannya. ${ }^{26}$

Dalam persoalan kalam, al-Shabuni berpedoman kepada madzhab ahlussnnah Asy'ariah, seperti melihat Allah diakhirat, 'arsy, tafsir ayat kursi, ayat-ayat mutajassimah (seperti tentang wajah Tuhan, istiwa'), meski terkadang berbeda dengan pendapat ulama salaf. Seperti penjelasan beliau tentang firman

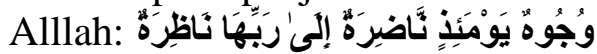

“ Setelah Allah menjelaskan bahwa manusia itu lebih mementingkan dunia dari pada akhirat, lalu Dia menjelaskan keadaan

\footnotetext{
${ }^{24}$ Muhammad Ali Al-Shabuni, Dalam Muqaddimah Shafwah al-Tafâsîr, 14.

25 A. Husnul Hakim Imzi, Ensiklopedi Kitab-kitab Tafsir Kumpulan Kitab-kitab Tafsir Dari Masa Klasik Sampai Masa Kontemporer, Cet. 1, (Depok: LSIQ, 2013), 208.

${ }^{26}$ A. Husnul Hakim Imzi, Ensiklopedi Kitab-kitab Tafsir Kumpulan Kitab-kitab Tafsir Dari Masa Klasik Sampai Masa Kontemporer, Cet. 1, (Depok: LSIQ, 2013), 209.
} 
manusia di akhirat, yang dibagi dalam dua kelompok, yaitu abrar (baik) dan fujur (buruk). Saat itu maka, wajah orang-orang yang baik akan terlihat cerah karena kegembiraan memperoleh kenikmatan surga. Maksudnya adalah mereka melihat keagungan Allah sehingga tenggelam di dalam jamaliyahNya. $^{27}$

Adapun corak yang digunakan dal Shafwah al-Tafâsîr ini adalah adab al-Ijtima'i (sosial kemasyarakatan). Walaupun al-Shabuni mahir dalam bidang syariah (fiqih) sebagaimana yang terlihat dalam biografinya, namun alShabuni tidak banyak membahas masalah fikih jika bertemu dengan ayat ahkam, adapun beliau banyak mengambil hikmah dari ayat yang ia bahas yang dikaitkan dengan masyarakat zaman sekarang. Karena sesuai dengan latar belakang tujuan penulisan kitab ini yaitu untuk memudahkan manusia untuk memahami Alquran.

\section{c. Penafsiran Ali al-Shabuni Tentang Ru'yatullah}

Ali Al-Shabuni ketika menafsirkan QS alQiyamah [75]: 22-23 "Wajah-wajah (orang mukmin) pada hari itu berseri-seri”; setelah menuturkan bahwa umat manusia mengutamakan dunia dan kenikmatannya yang fana atas akhirat serta kebahagiaannya yang abadi, Allah menjelaskan pembagian manusia pada hari kiamat menjadi dua bagian; orang yang berbakti dan orang yang durhaka. Makna ayat ini, wajah orang-orang yang berbakti pada hari kiamat bersinar, indah berseri dan bercahaya karena merasakan nikmat. Ini semakna dengan ayat. "Катu dapat mengetahuinya dari wajah kesenangan hidup mereka yang penuh kenikmatan". (Q.S al-Muthafifin [83]: 24). "Kepada Tuhannyalah mereka melihat"; wajah-wajah itu memandang keagungan Tuhannya dan mereka terbengong karena keelokan-Nya. Nikmat terbesar bagi penghuni surga adalah melihat Allah Yang Mulia tanpa tabir. Hasan Basri berkata, "Mereka melihat sang pencipta dan layak bagi mereka untuk berseri-seri ketika

${ }^{27}$ A. Husnul Hakim Imzi, Ensiklopedi Kitab-kitab Tafsir Kumpulan Kitab-kitab Tafsir Dari Masa Klasik Sampai Masa Kontemporer, Cet. 1, 209-210. mereka melihat Sang Pencipta. ${ }^{28}$ Hal tersebut disebutkan dalam nash-nash yang shahih. ${ }^{29}$

Dari Aspek Balaghah susunan kalimat وُجُوهُ يَوْمَيَذِ (wajah pada hari itu), menurut Ali al-Shabuni, susunan kalimat tersebut merupakan majaz mursal, yang dikatakan "wajah" namun yang dimaksudkan adalah keseluruhan. Ini termasuk mengucapkan sebagian namun bermaksud menyebutkan secara keseluruhan. ${ }^{30}$

Zamakhsyari menafsirkan ayat ini dengan mengatakan, bahwa kata nazhirah diartikan bukan melihat Tuhan, tetapi at-taqqu' wa arraja' yang berarti intazhara ila ni'matillah (menunggu nikmat Tuhan), agar sesuai dengan ideologi madzhabnya, yang berpemahaman bahwa di akhirat Tuhan tidak bisa dilihat dengan mata. ${ }^{31}$

Sedangkan kaum Asy'ariah menafsirkan ayat ini sebagai berikut:

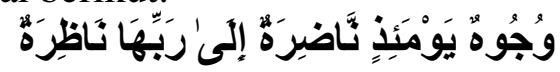

Menurut al-Asy'ariah kata nâzirah dalam ayat ini tak bisa diartikan dengan memikirkan, karena akhirat bukanlah tempat berfikir. Juga tak bisa diartikan menunggu, karena wujuh yaitu muka atau wajah tidak dapat menunggu, yang menunggu ialah manusia. oleh karena itu makna kata nazirah mesti berarti melihat dengan mata. ${ }^{32}$

${ }^{28}$ Muhammad Ali al-Shabuni, Shafwah al-Tafâsîr, Jilid 3, (Kairo: Darus Shabuni: 2009), 462

${ }^{29}$ Ini adalah madzhab Ahlu Sunnah wa al-Jama'ah. Madzhab ini dikuatkan dengan hadits yang tersebut dalam dua shahih. "Sesungguhnya kalian akan melihat Tuhan kalian dengan langsung sebagaimana kalian melihat bulan ini.." Dalam shahih Muslim disebutkan, "Maka tabir dibuka, maka mereka tidak diberi sesuatu yang lebih mereka sukai daripada melihat Tuhan mereka Tabaraka wa Ta'ala. "Kaum Muktazilah mengingkari kemungkinan melihat Allah diakhirat dan mereka menakwil kata نَاظِرِّة bahwa maksudnya adalah menanti paha Tuhannya. Takwil ini batil, sebab tidak sesuai dengan tata bahasa Arab. Lihat catatan kaki dalam kitab Shafwah al-Tafâsîr.

${ }^{30}$ Muhammad Ali al-Shabuni, Shafwah al-Tafāsîr, Jilid 3, 464.

31 Abdul Mustaqim, Pergeseran Epistemologi Tafsir, (Yogyakarta: Pustaka Pelajar, 2008), 135.

${ }^{32}$ Harun Nasution, Teologi Islam Aliran-aliran Sejarah Analisa Perbandingan, Cet. 5, (Jakarta: UI Press, 1986), 140. 
Ali al-Shabuni menafsirkan bahwa pada hari kiamat manusia terbagi menjadi dua golongan, yaitu orang yang berbakti dan orang yang durhaka. Dalam menafsirkan ayat رَبِّهَا نَاظِرِهُ terbesar bagi penghuni surga adalah melihat Allah Yang Mulia tanpa tabir. Jika dilihat dari doktrin kedua golongan diatas yaitu Muktazilah dan Ahlussunnah serta penafsiran Ali al-Shabuni dalam kitab Shafwah alTafâsîr tentang ayat ini, penulis berasumsi atau berkesimpulan bahwa ketika menafsirkan ayat ini Ali al-Shabuni sepaham dengan apa yang menjadi doktrin teologi ahlusunnah yang mengatakan bahwa diakhirat Tuhan dapat dilihat dengan mata kepala. Ini jelas terlihat dalam penafsirannya mengenai ayat ini. Juga ia tidak mentakwil kata nāzirah sebagaimana yang dilakukan oleh kaum Muktazilah. Karena menurut Ali al-Shabuni bahwa nikmat terbesar bagi penghuni surga adalah melihat Allah tanpa tabir, sebagaimana ayat ini dan yang dijelaskan dalam hadits shahih. Sebagai sebuah proses budaya, penafsiran Alquran yang sangat dipengaruhi (jika tidak "dideterminasi") ruang waktu, sangatlah wajar jika melahirkan keragaman.

\section{d. Penafsiran Ali al-Shabuni Tentang Sifat Allah dan Anthropomorfisme}

Ali al-Shabuni ketika menafsirkan QS AlNisa (4): 164 mengatakan bahwa, " Allah hanya menyebut Musa yang diajak bicara tanpa adanya perantara, oleh karena itu Musa disebut kalimullah (yang berbicara dengan Allah). Sedangkan penegasan lafadz takliman untuk menghilangkan kemungkinan majaz (figuratif). Tsa'lab berkata, "Jikalau tidak ada ta'kid (penegas), tentulah boleh diucapkan, "Aku telah berbicara denganmu mengenai fulan, bermakna: Aku telah mengutus kepadannya seorang utusan untuk diajak bicara, tapi manakala Allah berfirman takliman maka kalimat itu hanya berarti

33 Muhammad Solahudin, "Metodologi Dan Karakteristik Penafsiran Dalam Tafsir Al-Kashshaf," Wawasan: Jurnal Ilmiah Agama Dan Sosial Budaya 1, no. 1 (2016): 116. bentuk pembicaraan yang dapat didengarkan dari Allah. ${ }^{34}$

Mengenai ayat ini golongan Asy'ariah berpendapat, Allah berbicara langsung dengan Nabi Musa a.s dan karena itu Nabi Musa disebut kalimullah. Dan Allah berbicara dengan sifat-Nya. Karena Asy'ariah mempunyai paham bahwa Allah mempunyai sifat, dan Allah mengetahui segala sesuatu dengan sifat-Nya ${ }^{35}$.

Ali al-Shabuni dalam menafsirkan ayat tersebut, ia menafsirkan bahwa Allah berbicara dengan Musa secara langsung tanpa adanya perantara, dan oleh karena itu Musa disebut kalimullah. Serta adanya lafadz takliman untuk menghilangkan kemungkinan adanya majaz. Dan kata takliman menjadi penegas. Oleh karena itu menurut hemat penulis, jika dilihat dari penafsiran Ali alShabuni diatas, ia sepakat dengan teologi Asy'ari bahwa Allah berbicara langsung dengan Nabi Musa.

\section{1) Ketika menafsirkan al-Sajdah [32]: 4}

"Allah lah yang menciptakan langit dan bumi dan apa-apa yang diantara keduanya dalam enam masa," Allah, Dia-lah yang menciptakan langit yang tinggi dan kokoh, bumi lengkap dengan keajaiban-keajaibannya dan makhluk-makhluk yang ada diantara keduanya kira-kira dalam enam hari. Al-Hasan berkata: Yakni dari hari-hari dunia. Seandainya Allah berkehendak untuk mengajarkan agar para hamba berhati-hati dalam setiap urusan. Al-Qurthubi berkata: Allah memperlihatkan kepada mereka, bahwa kekuasaan-Nya sempurna agar mereka mendengarkan Alquran dan merenungkannya. Menciptakan adalah membuat setelah tiada dan belum berupa apa pun. " Kemudian ia bersemayam diatas Arsy," dengan semayam yang layak bagi kebesaran-Nya tanpa menyerupakan Allah maupun menyamakanNya dengan sesuatu apa pun. "Tidak ada bagi

\footnotetext{
${ }^{34}$ Muhammad Ali al-Shabuni, Shafwah al-Tafāsîr, Jilid 1, (Kairo: Darus Shabuni, 2009), 295.

35 Qosim, "Analysis of Critical Thought Wahbah Wahbah Az-Zuhailī Concerning Determination Separations, ” Jurnal Studi Agama Dan Masyarakat 10, no. 2 (2016): 233-256.
} 
kalian selain dari-Nya seorang penolongpun dan tidak (pula) seorang pemberi syafaat," kalian hai umat manusia, tidak mempunyai penolong yang menghalangi kalian dari siksaNya maupun pemberi syafaat yang menyafaati kalian di sisi-Nya selain Allah, kecuali dengan izin-Nya. dial ah yang mengurusi kemaslahatan kalian dan mengaturu urusan kalian. "Maka apakah kamu tidak memperhatikan," tidakkah kalian memikirkan hal tersebut, kemudian kalian beriman ? $^{36}$

Tentang antrofomorfisme, yakni anggapan bahwa Tuhan menyerupai manusia, Asy'ariah menyatakan bahwa Allah mempunyai wajah, mata, penglihatan dan tangan, namun semua itu tidak dapat digambarkan bagaimana keadaannya dan tidak dapat ditentukan bentukannya (tafwidh). Demikian pula pernyataan bahwa Allah duduk diatas singgasana.Dikatakan pula bahwa Allah mempunyai pengetahuan ( $\mathrm{al}$ - $\mathrm{ilm}$ ), pendengaran (al-sam'), penglihatan (al-bashar) dan kekuatan (quwwah). Pendapat ini diambilnya dari pernyataan-pernyataan didalam Alquran mengenai Allah. Ia memahami pernyataanpernyataan itu secara harfiah, ${ }^{37}$ Kaum Asyari juga tidak menerima antrofomorphisme dalam pengertian bahwa Tuhan mempunyai sifatsifat jasmani yang sama seperti sifat-sifat jasmani manusia. Sungguhpun demikian mereka tetap mengatakan bahwa Tuhan sebagaimana disebut dalam Alquran mempunyai mata, muka dan tangan, tetapi muka, mata, tangan itu tidak sama dengan yang ada pada manusia. Mereka berpendapat bahwa kata-kata ini tidak boleh diberi interpretasi lain. Melainkan diserahkan saja kepada Tuhan. Tuhan mempunyai mata, muka, tangan, tak dapat diberikan gambaran atau definisi. ${ }^{38}$

Sedangkan jika dilihat dari penafsiran Ali

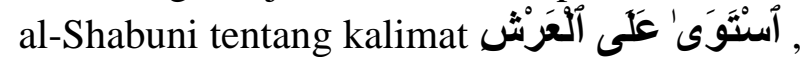
ia menafsirkan "Dengan semayam yang layak

\footnotetext{
${ }^{36}$ Muhammad Ali al-Shabuni, Shafwah al-Tafâsîr, Jilid 2, (Kairo: Darus Shabuni, 2009), 460-461.

37 Machasin, Islam Teologi Aplikatif,(Yogyakarta: Pustaka Alif, 2003), 32.

38 Harun Nasution, Teologi Islam Aliran-aliran Sejarah Analisa Perbandingan, 137-138.
}

bagi kebesaran-Nya tanpa menyerupakan Allah maupun menyamakan-Nya dengan sesuatu apapun." Menurut hemat penulis, penafsiran Ali al-Shabuni ini menggunakan tafwidh, yaitu menyerahkan kembali kepada Allah. Dalam artian, mungkin saja Allah bersemayam diatas "Arsy", namun bagaimana ia bersemayam, diserahkan kembali kepada Allah tanpa menyerupakannya dengan sesuatu apapun. Oleh karena itu penafsiran Ali alShabuni ini sama dengan paham teologi Asy'ariah.

\section{2) QS Shaad [38]: 75}

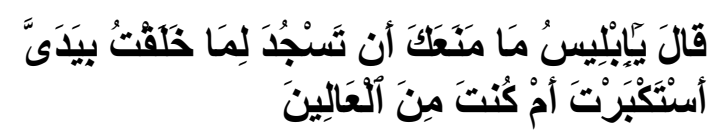

Yang menjadi fokus pembahasan di ayat diatas yaitu kata بَيََّى ( kedua tangan-Ku). Dalam menafsirkan kata itu, Ali al-Shabuni mengartikan tangan dengan "Dzatku", itu mengindikasikan Ali al-Shabuni mentakwil kata tersebut. Sehingga maknanya menjadi "Adam yang aku ciptakan dengan (dzat$\mathrm{Ku})$ ". 39 walaupun demikian ini bukan penafsiran yang salah. Karena dalam memahami lafadz tersebut atau semisalnya, ada dua metode yang dapat digunakan, yaitu tafwidh dan takwil. Sebagaimana imam-imam ahlusunnah. Dalam menafsirkan ayat ini, Ali al-Shabuni menggunakan metode takwil tanpa harus merubah lafadz ayat (tashrif).

\section{3) Penafsiran Ali al-Shabuni Tentang Perbuatan Tuhan dan Manusia}

Dalam Shafwah al-Tafâsîr al-Shabuni menafsirkan ayat ini QS al-Saffat [37]: 96 yaitu, "Padahal Allah yang menciptakan kamu dan apa yang kamu lakukan itu," ia berkata, sedangkan Allah menciptakan kalian dan menciptakan perbuatan kalian serta segala sesuatu merupakan makhluk-Nya? bagaimana kalian menyembah makhluk dan tidak menyembah pencipta? Bukankah kalian punya akal wahai umat manusia? Ibnu Jazzi berkata, "Sebagian ulama tafsir berpendapat, bahwa maksudnya Allah mencipta kalian dan

\footnotetext{
${ }^{39}$ Muhammad Ali al-Shabuni, Shafwah al-Tafâsîr, Jilid 3, (Kairo: Darus Shabuni, 2009), 60.
} 
perbuatan kalian dan ayat ini menjadi dasar bahwa perbuatan hamba adalah makhluk. Sebagian ulama berpendapat, maksud ayat ini adalah Allah menciptakan kalian dan menciptakan berhala yang kalian buat. Pendapat kedua lebih sesuai dengan konteks firman dan lebih kuat untuk menjadi hujah atas para penyembah berhala. ${ }^{40}$

Ada dua konklusi mengenai ini, yakni secara ringkasnya bahwasannya Tuhan yang menciptakan perbuatan manusia. Ini merupakan konklusi dari pihak ahlussunnah. Ahlussunnah melihatnya dari aspek keagungan-Nya, karena itu menurut mereka hanya Allah yang mencipta, tiada pencipta selain-Nya. Sedangkan konklusi kedua mengatakan, bahwa manusialah yang menciptakan perbuatannya sendiri. Ini merupakan konklusi dari muktazilah. Asyari berargumen dengan mengambil surat al-Saffat ayat 96 diatas. Menurutnya Asy'ari, wa ma ta'malun disini diartikan "apa yang kamu perbuat" dan bukan "apa yang kamu buat". Dengan hal tersebut ayat ini mengandung pengertian bahwa Allah menciptakan kamu dan perbuatan-perbuatan kamu. Jadi, dalam paham Asyari, perbuatan-perbuatan manusia adalah diciptakan Tuhan. ${ }^{41}$

Sedangkan jika dihubungkan dengan penafsiran dari al-Shabuni dalam kitabnya Shafwah al-Tafasir dalam ayat ini, al-Shabuni mengutip pendapatnya ibn Jazzi yang mengatakan bahwa Allah menciptakan kalian dan perbuatan kalian. Serta dalam konteks ayat ini yaitu bahwasanya Allah yang telah menciptakan kalian dan menciptakan berhala yang kalian buat, dan ini sesuai dengan konteks ayat. Konteks ayat ini berbicara mengenai umat Nabi Ibrahim yang menyembah berhala pada waktu itu. Seperti hadis berikut yang mengatakan penyembah berhala juga ada setelah masa Nabi. "Sesungguhnya akan keluar dari keturunan orang ini satu kaum; yang membaca Alquran, namun tidak melewati kerongkongan-nya.

\footnotetext{
${ }^{40}$ Muhammad Ali Al-Shabuni, Shafwah al-Tafâsîr, Jilid 3, (Kairo: Darus Shabuni, 2009), 35.

${ }^{41}$ Harun Nasution, Teologi Islam Aliran-aliran Sejarah Analisa Perbandingan, 108.
}

Mereka membunuh kaum muslimin dan membiarkan para penyembah berhala. Mereka akan keluar dari Islam ini sebagaimana keluarnya anak panah dari buruannya. Jika sekiranya aku menemui mereka, pasti aku bunuh mereka seperti terbunuhnya kaum 'Aad." (HR. Bukhari Muslim)",42.

Jika dilihat dari penafsiran al-Shabuni dalam konteks ayat ini yaitu "Allah menciptakan kalian dan menciptakan berhala yang kalian buat", itu berarti bahwa sesungguhnya diciptakannya berhala oleh umat Nabi Ibrahim hakikatnya Allah lah yang menciptakan berhala itu. Karena Allah yang menciptakan perbuatan manusia. Manusia bukanlah sebagai pencipta, karena tidak ada pencipta selain dari Tuhan. Sungguhpun demikian, dalam perwujudan perbuatannya manusia mempunyai bagian, walaupun bagian tidak efektif. Dengan kata lain, yang mewujudkan perbuatan manusia, sebenarnya adalah Tuhan sendiri. Oleh karena itu Ali alShabuni mengatakan, "Allah menciptakan kalian dan menciptakan perbuatan kalian serta segala sesuatu merupakan makhluknya". dan sependapat dengan perkataan sebagian ulama yang dikutip dari ibnu Jazzi bahwa Allah menciptakan kalian dan menciptakan berhala yang kalian buat. Pendapat ini pula yang menjadi hujah atas para penyembah berhala.

\section{e. Kecenderungan Ali al-Shabuni Dalam Menafsirkan Ayat-ayat Teologi}

Jika dilihat dari pemaparan mengenai pembahasan ayat-ayat teologi diatas, bisa diketahui bahwasannya Ali al-Shabuni dalam menafsirkan ayat-ayat teologi mempunyai kecenderungan, secara umum yaitu ahlussunnah Asy'ariah.

\section{SIMPULAN}

Dalam menafsirkan ayat-ayat teologi, Ali al-Shabuni mempunyai kecenderungan, dalam hal ini yaitu teologi Asy'ariah. Di dalam tafsir Shafwah al-Tafâsîr, Ali al-Shabuni ketika menafsirkan tentang ru'yatullah dalam surat

42 Afroni, "Makna Ghuluw Dalam Islam: Benih Ekstremes Beragama." 
al-Qiyamah [75]: 22-23, ia sepaham dengan teologi Asy'ari bahwa Tuhan bisa dilihat diakhirat kelak. Dalam menafsirkan surat alNisa [4]: 164 tentang Allah berbicara dengan Musa, ia pun cenderung dengan teologi Asy'ari, bahwasannya Allah berbicara dengan Musa secara langsung. Dalam menafsirkan masalah anthropomorfhisme dalam surat asSajdah [32]: 4, Ali al-Shabuni sepaham dengan teologi Asy'ari. Dalam menafsirkan kata بَيَََ pada surat Shaad [38]: 75, ia cenderung ahlussunnah karena dalam memahami ayat seperti ini ahlussunnah menggunakan dua metode, yaitu tafwidh dan takwil. Dalam menafsirkan tentang perbuatan Tuhan dan manusia yaitu surat al-Saffat [37]: 96, ia cenderung sepaham dengan teologi Asy'ari, yang mengatakan bahwa Allah yang menciptakan kalian dan perbuatan kalian. Ini menandakan bahwa perbuatan manusia adalah makhluk.

\section{DAFTAR PUSTAKA}

Abidu, Yunus Hasan, Tafsir al-Quran Sejarah Tafsir dan Metode Para Mufasir, terj. Oleh Qodirun Nur dan Ahmad Musyafiq Dari Judul Asli Dirasat Wa Mabahits Fi Tarikh al-Tafsir Wa Manahij al-Mufasirin, Jakarta: Gaya Media Pratama, 2007

Anwar, Rosihon, Dadang Darmawan, and Cucu Setiawan. "Kajian Kitab Tafsir Dalam Jaringan Pesantren Di Jawa Barat." Wawasan: Jurnal Ilmiah Agama dan Sosial Budaya 1, no. 1 (2016): 56-69.

Baidan, Nashruddin, Rekonstruksi Ilmu Tafsir, Jakarta: PT Dana Bhakti Prima Yasa, 2000

Dzahabi, M. Husein, Penyimpanganpenyimpangan Dalam Penafsiran al Quran,Diterjemahkan oleh, Hamim Ilyas dan Mazhnun Husein Dari Judul Asli, AlIttija Hatul Munharifah Fi Tafsiril Quranil Karim, Ed. 1, Cet. 4, Jakarta: PT Raja Grafindo Persada, 1996

Fachrudin al-Razi, Mafatih al-Ghaib, CD alMaktabah asy-Syamilah

Goldziher, Ignaz, Mazhab Tafsir dari Aliran Klasik Hingga Modern, terj. Oleh M. Alaika Salamullah, Saifydin Zuhri dan
Badrus Syamsul Fata, cet. 1, Yogyakarta: Elsaq Press, 2003

Hanafi, Ahmad, Theologi Islam (Ilmu Kalam), cet. 3, Jakarta: Bulan Bintang, 1979

Hikmawati, Fenti. "Islamic Counselling Model to Increase Religious Commitment (Study of Students at the University UIN Bandung)." International Journal of Nusantara Islam 1, no. 1 (2013): 65-81.

Imzi, A. Husnul Hakim, Ensiklopedi Kitabkitab Tafsir Kumpulan Kitab-kitab Tafsir Dari Masa Klasik Sampai Masa Kontemporer, Cet. 1, Depok: LSIQ, 2013

Iskandar, Syahrullah. "Studi AlQuran Dan Integrasi Keilmuan: Studi Kasus UIN Sunan Gunung Djati Bandung." Wawasan: Jurnal Ilmiah Agama dan Sosial Budaya 1, no. 1 (2016): 13-14.

Khaeruman, Badri, Sejarah Perkembangan Tafsir al-Quran, Bandung: Pustaka Setia, 2004

Machasin, Islam Teologi Aplikatif,Yogyakarta: Pustaka Alif, 2003

Masripah. "Indonesian Islamic Women Movement (A Case Study of Bkswi West Java)." International Journal of Nusantara Islam 1, no. 2 (2013): 9-21.

Mustakim, Abdul, Pergeseran Epistemologi Tafsir, Yogyakarta: Pustaka Pelajar, 2008

Nasution, Harun, Teologi Islam Aliran-aliran Sejarah Analisa Perbandingan, Cet. 5, Jakarta: UI Press, 1986

Nata, Abuddin, Metodologi Studi Islam, cet. 20, Jakarta: Rajawali Pers, 2013

Qosim. "Analysis of Critical Thought Wahbah Wahbah Az-Zuḥailī Concerning Determination Separations." Jurnal Studi Agama dan Masyarakat 10, no. 2 (2016): 233-56.

Saputra, Riki. "Religion And The Spiritual Crisis Of Modern Human Being In The Perspective Of Huston Smith 'S Perennial Philosophy." Al-Albab 5, no. 2 (2016): 195-215.

Shabuni, Muhammad Ali, Shafwah al-Tafâsîr, Jilid 3, Kairo: Darus Shabuni: 2009

Solahudin, Muhammad. "Metodologi Dan Karakteristik Penafsiran Dalam Tafsir AlKashshaf." Wawasan: Jurnal Ilmiah 
Agama dan Sosial Budaya 1, no. 1 (2016): Zamakhsyari, al-Kasysyaf, CD al-Maktabah 116-26. asy-Syamilah 